\title{
Crooke Hyaline Change
}

National Cancer Institute

\section{Source}

National Cancer Institute. Crooke Hyaline Change. NCI Thesaurus. Code C154341.

Intracytoplasmic accumulation of cytokeratin. 